\title{
The utility of expectational data: Firm-level evidence using matched qualitative-quantitative UK surveys*
}

\author{
Silvia Lui, James Mitchell and Martin Weale \\ National Institute of Economic and Social Research
}

October 6, 2010

\begin{abstract}
Qualitative expectational data from business surveys are widely used to construct forecasts. But, based typically on evaluation at the macroeconomic level, doubts persist about the utility of these data. This paper evaluates the ability of the underlying firm-level expectations to anticipate subsequent outcomes. Importantly this evaluation is not hampered by only having access to qualitative outcome data obtained from subsequent business surveys. Quantitative outcome data are also exploited. This required access to a unique panel dataset which matches firms' responses from the qualitative business survey with these same firms' quantitative replies to a different survey carried out by the national statistical office. Nonparametric tests then reveal an apparent paradox. Despite evidence that the qualitative and quantitative outcome data are related, we find that the expectational data offer rational forecasts of the qualitative but not the quantitative outcomes. We discuss the role of "discretisation" errors and the loss function in explaining this paradox.
\end{abstract}

\footnotetext{
*We thank the CBI and the ONS for their help in facilitating this project, with particular thanks to Lai Co (CBI), Rhys Davies (ONS), Robert Gilhooly (ONS), Felix Ritchie (ONS), Eric Scheffel (ONS), Richard Welpton (ONS) and Jonathan Wood (CBI). Thanks to two anonymous referees for helpful comments. We gratefully acknowledge financial support from the ESRC (Award Reference: RES-06223-0239) and the Bank of England. This work contains statistical data from ONS which are Crown copyright and reproduced with the permission of the controller of HMSO and Queen's Printer for Scotland. The use of the ONS statistical data in this work does not imply the endorsement of the ONS in relation to the interpretation or analysis of the statistical data. This work uses research datasets which may not exactly reproduce National Statistics aggregates. For more details about the CBI's ITS, please go to http://www.cbi.org.uk/ndbs/content.nsf/802737AED3E3420580256706005390AE/2F172E85D0508CEA80256E20003E95C6.
} 


\section{Introduction}

Qualitative business surveys are widely seen as an important complement to official data. These surveys typically ask businesses to provide qualitative categorical answers to a number of questions including what has happened to their output in the recent past and what they expect to happen to their output in the near future. Respondents say whether output has fallen, stayed the same or risen and which of the three they anticipate over some specified future period. The importance that the European Commission attaches to such surveys can be seen from the fact that it meets a part of their costs and publishes their findings monthly. The Bank of England refers to them in its minutes (Bank of England (2010)) and it is clear that the European Central Bank also regards them as informative; e.g., see Trichet (2009). As compared to official data they have two major attractions. First they are more timely. Secondly they provide indicators of expectations as well as outcomes. Expectational data are used widely by forecasters on the assumption that they tell them something useful about what will happen to the economy in the future.

Despite the growing interest in micro data, analysis of such data focuses, almost universally, on aggregate summaries of the findings. Such summaries typically show the proportions of the respondents in each of the three categories mentioned above. Or they are limited to indicating the "balance of opinion"- the difference between the proportion of those expecting or reporting a rise and those expecting or reporting a fall. For example, the cross-country expectational business survey data archived by the European Commission are presented in this latter form. These data are available at http://ec.europa.eu/economy_finance/db_indicators/surveys/.

However, a small but growing literature has peered into the 'black box' to examine the underlying firm-level qualitative data. When these data take the form of a panel, such that it is possible to keep track of the expectations and outcomes as reported by individual firms, then it is possible to test their utility directly. One can test whether firms' expectations are, in any statistical sense, coherent with the outcomes that they subsequently report. There have been a few applications of such tests. Nerlove (1983) compared French and German firms' qualitative expectations with their subsequent qualitative reports of what actually happened using $3 \times 3$ contingency tables constructed from their trichotomous ordered responses. Horvath et al. (1992) and Ivaldi (1992) tested rationality using the (polychoric) correlation matrix between the categorical variables.

There are, in fact, two types of analysis which can profitably be carried out using such 
micro data. The first is an examination of the answers that businesses give to different questions in the survey, with the comparison of the qualitative expectations they report in one survey and the qualitative outturn they report in a subsequent survey being only one example. The second is a comparison of the answers businesses give in qualitative surveys with the quantitative data that the same firms provide in (usually distinct) surveys such as those used in compiling output indices and national accounts. Obviously for this second type of analysis to be carried out, it is necessary to obtain or generate matched data sets which contain the answers of a given firm to both types of survey. We are not aware of business surveys being analysed in this way previously, perhaps because of the difficulties in obtaining suitable data. There are, however, studies of household expectations and quantitative and qualitative outcomes. These are facilitated because the same survey typically collects both types of data. For example Das et al. (1999) look at the Dutch Socio-Economic Panel.

In this paper we draw on a panel dataset of UK manufacturing firms' responses to the Industrial Trends Survey, run by the Confederation of British Industry, and the Monthly Production Inquiry, run by the Office for National Statistics. This dataset matches firms' responses from a leading qualitative business survey with these same firms' quantitative replies to a different official survey carried out by the national statistical office. We then test the ability of firm-level expectations to anticipate subsequent outcomes. Extending previous work, this evaluation exploits both qualitative and quantitative outcome data. Specifically, we use and develop nonparametric tests for the rationality of the firm-level qualitative expectational data. Rationality tests remain a useful tool in assessing the utility of expectational data. This is because under rationality outcomes do not differ systematically (i.e., regularly or predictably) from what was expected. But for qualitative expectations data implementation of rationality tests requires additional auxiliary assumptions to be made which are tested jointly with rationality. We therefore follow Manski (1990) and Das et al. (1999) and, more accurately, refer to the tests as tests of the "best-case scenario". In particular, we discuss how the implications of rationality depend on the firm's loss function. Under rationality different loss functions result in different categorical predictions, given the firm's subjective density forecast. We therefore follow Das et al. (1999) and conduct tests when firms report the mode, the median (more generally the alpha-quantile) or the mean of their subjective density forecast of future output growth. These tests follow Manski (1990) and identify bounds on the distribution of realised outcomes conditional on firms' qualitative expectations under 
the assumption of rational expectations.

As well as testing the ability of the expectational data to forecast the two distinct outcome variables, we test what we call the coherence between these qualitative and quantitative outcome measures. This involves testing whether the two outcome variables are measuring the same concept of output growth, as implicitly assumed when outcome data from qualitative business surveys are used to provide a contemporaneous indication (nowcast) of economic activity. With its access to a unique matched panel dataset this paper represents, to the best of our knowledge, the first application of these tests to business surveys of the type routinely used by forecasters.

The next section explores previous uses and tests of expectational data. It motivates our use of nonparametric tests to judge the utility of these data when collected in qualitative business surveys and available at the micro-level. It also explains why we prefer to speak of the specific rationality tests employed as tests of the "best-case scenario", given that auxiliary assumptions need to be made to operationalise the rationality test with categorical expectations data. Section 3 provides a description of the data that we use. We then present our notation in Section 4. This is followed in Section 5 by a detailed discussion of the tests that can be carried out on these expectations data. Section 6 describes the results of the tests and Section 7 concludes.

\section{Background}

Expectations are subjectively held beliefs of individuals or firms about uncertain future outcomes. Most published expectations data are concerned with point expectations, although recently there has been increased interest in density expectations or forecasts; e.g., see Hall \& Mitchell (2009). Density forecasts provide an estimate of the probability distribution of the possible future values of the variable and represent a complete description of forecast uncertainty. In contrast, point expectations represent just one feature of this subjective density. As we discuss below, which feature is extracted depends on the forecaster's loss function. Our focus is on qualitative point expectations, since business surveys tend to take this form. But importantly, depending on the forecaster's loss function, we evaluate these expectational data relative to both qualitative and quantitative outcome or realisations data. 


\subsection{Uses of expectational data}

Expectational data continue to be used widely as leading indicators by forecasters. For some recent examples published in the International Journal of Forecasting see Kauppi et al. (1996), Hansson et al. (2005), Abberger (2007) and Claveria et al. (2007). Expectational data are also used in conjunction with other variables when forecasting. Factor models, for example, are a popular tool to produce forecasts from a large set of indicator variables, only some of which may be expectational variables; see Stock \& Watson (2002) and Forni et al. (2001). The use of expectational data is predicated on the hope that models that include expectational information deliver more accurate forecasts than models without expectations. Typically these expectational data are considered in "aggregate" form, as proportions of the respondents in each of the three categories, considered above, or as the balance of opinion. An exception is Mitchell et al. (2005) who considered how to construct indicators of the aggregate of interest from the underlying qualitative firm-level panel dataset. Their indicator gives more emphasis to firms whose qualitative answers have a close link to the official data than to those whose expectations correspond only weakly or not at all.

Expectational data are also used to test different models of expectations formation, notably rationality (see Section 2.2 below). They are also used to test different economic theories. For examples, see Nerlove (1983), McIntosh et al. (1989), Horvath et al. (1992), Carroll et al. (1994), Branch (2004), Easaw \& Heravi (2004) and Souleles (2004). As well as the European Commission's qualitative business surveys, qualitative expectational data are also collected for Japan by Tankan and for the US by the Michigan Survey of Consumer Attitudes and Behavior and The Conference Board.

Quantitative expectations data, typically forecasts from professional economists, are also available from Consensus Economics (for most countries in the world), Blue Chip Economic Indicators (principally the US), the Livingstone Survey (US) and the Survey of Professional Forecasters (US). Having the expectations data in quantitative form is more informative. But the number of forecasters, $N$, surveyed is much smaller (typically $N<100$ ) than in business surveys of the sort we study in this paper, where $N$ is typically at least ten times bigger.

Nevertheless, doubts persist about the quality and utility of these expectational data. This is explained, at least in part, by the qualitative nature of data typically available from business tendency surveys. Other reasons include a priori concerns that respondents do not mean what they say when subjectively replying to surveys; e.g., see 
Bertrand \& Mullainathan (2001). There are also a posteriori doubts. This is because of mixed empirical evidence on: (i) whether models with expectations data deliver more accurate forecasts than models without expectations data and (ii) whether expectations are formed "rationally", a term we define below. Pesaran \& Weale (2006) provide a survey of this evidence, with the findings of Claveria et al. (2007) exemplifying the inconclusive evidence on the utility of expectational data when forecasting. Moreover, in a recent application Wheeler (2010) found that while recessions in the UK have been preceded by large deteriorations of expectations, the expectational data have given false signals in the past.

This paper extends the coverage of empirical work by assessing the utility of these qualitative expectational data at the firm level not just in terms of their relationship with firms' own retrospective but qualitative reports of their output growth but with these same firms' quantitative answers.

\subsection{Rationality}

Tests of the rationality of expectations remain a useful first step in establishing the utility of expectational data. But the specific rationality test implemented, and the auxiliary assumptions needed, depend on the nature of the available expectations data. In particular, the test depends on whether aggregated (macro) data or micro data are used. It also depends on whether the expectations data are available in quantitative or qualitative form.

The rational expectation is defined as the "objective" expectation of the outcome conditional on the set of all information relevant to the determination of the outcome available at the time the expectation was made. With rationality, outcomes do not differ systematically (i.e., regularly or predictably) from what was expected. People know "how the world works" and their ("generalised" - discussed further below) forecasting errors are unbiased, serially uncorrelated at the single period horizon and orthogonal to information known at the time the forecast was made; see Patton \& Timmermann $(2007 a)$. When coupled with the assumption that people form their point forecasts under a mean squared error loss function rational point forecasting errors share these properties. But more generally, as shown by Patton \& Timmermann (2007a), it is a transformation of the forecasting error called the generalised error that possesses these properties under rationality. This transformation accommodates the fact that rational forecasters may not be attempting to minimise expected mean squared error loss, but a 
more general potentially asymmetric loss function.

When the expectation takes the form of a density forecast, rationality requires equality of this subjectively formed density with the objective probability density function from which the outcome is drawn. Mitchell \& Wallis (2010) review tests for the equality of these two densities, operational when, as is usual in practice, we do not observe the objective density itself but a draw from it. But more commonly, as with the case we discuss below, only a point expectation is available.

\subsubsection{Aggregate tests}

In the absence of expectations data joint tests of rationality are required, since expectations are typically inferred from observed aggregate data conditional on a behavioural model (e.g., see Wallis (1980)). This means any test for rationality also depends on the choice of behavioural model. But the availability of (point) expectations data facilitates direct tests of rationality. Most studies have tested rationality assuming mean squared error loss. This involves testing the unbiasedness and efficiency of the expectations data (e.g., see Brown \& Maital (1981); and Clements \& Hendry (1998), pp. 56-59, for a textbook discussion). But tests under more general, asymmetric loss have also been developed. They reflect the aforementioned fact that it is the generalised forecasting error that is conditionally and unconditionally unbiased; see Patton \& Timmermann $(2007 a, 2007 b)$. With asymmetric loss, rational forecasts need not be the same as conditional mathematical expectations. In other words, it can be rational for forecasters to make biased forecasts under asymmetric loss; see Zellner (1986).

When, as is common with business surveys, the expectations data are available only in qualitative form, these rationality tests are typically applied after the qualitative data have been aggregated (to show the proportions of the respondents in each of the three categories mentioned above) and quantified. In the literature, different methods have been proposed for converting qualitative data into a quantitative measure of agents' opinions and intentions. Approaches suggested have included the probability method (Carlson \& Parkin (1975)) and the regression method (Pesaran (1984, 1987)) plus variants of these. See Driver \& Urga (2004) and Pesaran \& Weale (2006) for surveys.

\subsubsection{Disaggregate tests}

Keane \& Runkle (1990) and Bonham \& Cohen (2001) argued that, because of 'microheterogeneity', these tests for rational expectations should not be carried out on (ag- 
gregated) macro data or averaged ('consensus') forecasts. Instead they should be undertaken at the micro (individual or firm) level. When these micro expectations data are quantitative, as in Keane \& Runkle (1990) who study what later became the Survey of Professional Forecasters, tests of unbiasedness and efficiency can again be applied but at the micro level.

But to test the rationality of micro expectations data from qualitative business surveys, as in Section 5 below, requires a different approach. We follow Das et al. (1999) and employ nonparametric tests. This obviates the need to estimate parametric models relating the expectational and outcome data. Estimation of such parametric models would be problematic, given that panel expectational data are typically so unbalanced; moreover estimation relies on modelling assumptions, such as normality, which are often hard to validate. The nonparametric tests involve testing implications of rationality. With rationality, restrictions or bounds on the distribution of realised outcomes can be derived conditional on firms' qualitative expectations. We show in Section 5 that while qualitative expectational data, even under rationality, cannot tell us exactly what is going to happen, they do imply bounds. Manski (1990) previously studied this problem for binary, rather than ordered, survey responses. Statistical tests ( $t$-tests), as we explain, are then undertaken to test whether the expectational data respect the bounds implied by rationality.

But implementation of these tests does require additional, auxiliary assumptions to be made. This motivates Das et al. (1999) to classify these nonparametric rationality tests as tests of the "best-case scenario" 1] In particular, rationality is tested jointly:

(i) with an assumption on which feature of the firm's subjective density forecast is reflected by the qualitative point expectation; and

(ii) with an assumption that the outcome data, whether qualitative or quantitative, are independent across firms.

We consider three different assumptions about which feature of firm's subjective density forecast is reflected by the qualitative point expectation. These involve firms reporting their qualitative expectation with the mode, median or mean of their subjective density in mind. In each case, a distinct test of the best-case scenario is constructed. Crucially, when firms have the mode or median of their subjective density in mind, tests

\footnotetext{
${ }^{1}$ If the best-case scenario is unrealistic then the expectational data contain (even) less information than the bounds imply.
} 
of the best-case scenario exploit the (retrospective and prospective) qualitative business survey data only. But when they have the mean in mind, tests require knowledge of the quantitative outcome data.

The second assumption above rules out the possibility of macroeconomic (common) shocks, which would induce dependence in the outcome data across firms. This assumption is needed to construct the limiting distribution for the test statistics introduced below. Below, in Section 6.3, we briefly consider the independence issue further. For quantitative outcome data we consider how ex post one can identify common (macroeconomic) shocks and control for them when testing the rationality and utility of the expectational data.

We also introduce a weaker test than rationality. This is a test of whether, when firms have the mean of their subjective density in mind, the expectational data contain any signal, which might be useful to forecasters, about the quantitative outcome data. We also suggest a means of testing what we call the "coherence" between the retrospective qualitative data and the quantitative outcome data. This is important, given that these data are from different surveys, with different sampling and data measurement assumptions. But the widespread use of retrospective qualitative business surveys, whether at the micro or macro level, to provide more timely estimates or 'nowcasts' of the quantitative data (e.g., see Matheson et al. (2010)) is implicitly predicated on the assumption that the two samples are measuring the same concept of output growth. The proposed test of coherence, using the unique matched dataset, provides a means of testing this assumption.

\section{Data}

We draw on two quite distinct data sets. The Industrial Trends Survey (ITS), collected by the Confederation of British Industry (CBI), is a monthly survey which asks about 900 firms a range of questions. We focus on two:

1. "Excluding seasonal variations, what has been the trend over the past three months with regard to the volume of output?" (i.e. retrospective view)

2. "Excluding seasonal variations, what are the expected trends for the next thre ${ }^{2}$ months with regard to volume of output?" (i.e. prospective view).

\footnotetext{
${ }^{2}$ Until May 2003 firms were asked about past and future movements over a four-month period.
} 
Firms reply "down", "same" or "up". We have disaggregate information on this survey for the period January 2000 to December 2004. The combination of sample rotation and non-response mean that, over this period, a total of 2584 distinct firms replied. A further five did not want their returns used in this study.

The second survey is the Monthly Production Inquiry (MPI) run by the UK's Office for National Statistics (ONS). This collects monthly information on turnover. It is used to construct the Index of Production, which feeds directly into the national accounts. About 9000 firms are included in this survey each month. The MPI asks firms about their turnover while the ITS asks about output. The difference between these is accounted for by the change in stocks of finished goods and work in progress. This means that the comparison that we make is between monthly sales as reported to the ONS and the response to the ITS which should indicate what is happening to output. When fluctuations in sales growth are not met from stocks, and lead directly to output movements, the MPI and the ITS responses should have a close direct relationship 3 The MPI data are reported in current prices. We convert these to volume changes using the same process as does the ONS in its production of the Index of Production. The turnover reported by each firm is deflated by the 4-digit producer price index relevant to that firm's principal product. In addition, 5\% Winsorisation on each of the upper and lower tails of the distribution of these output growth rates, pooled across firms for each period, is carried out to mitigate the possible effects of outliers. Two-tailed Winsorisation (Dixon 1960) involves replacing those values of a variable below the lower or above the higher $x$-percentile with the values observed at those percentiles. It is generally preferred to trimming as a means of dealing with outliers. We discuss the effects of Winsorisation as we present our results.

Figure 1 shows the timing of the two surveys. The right-hand-side of Figure 1 explains the importance of the CBI survey. It shows the publication lag for data referring to the reference period to/from month $t$. Collection of the CBI survey begins about a week before the end of month $t-1$ and the survey results are published about a week before the end of month $t$ as indicating the state of business in month $t$. Firms fill in their ITS forms some time between the beginning of the last week of month $t-1$ and the middle of month $t$. If all firms do, in fact, wait until the last minute to fill in the survey

\footnotetext{
${ }^{3}$ Strong seasonal patterns in the firm-level MPI data could also weaken any relationship with the ITS data, given that firms are asked to reply to the ITS having adjusted for seasonal factors. The firm-level MPI data are seasonally unadjusted; given the unbalanced nature of the MPI panel they are adjusted by the ONS only after a degree of aggregation. In any case, inspection of the results below indicated no obvious seasonality in the utility of the expectational data.
} 
then the survey relates, in large part, to month $t$. However, the survey will contain little current month information if firms reply earlier. In contrast, the official ONS MPI data indicating the state of business in month $t$ are collected after month $t$ is complete and the results are published about a week after the start of month $t+2$. Thus, in fact, the CBI publishes a survey for month $t$ before official data for month $t-1$ are available. Nevertheless, it is clear from the time-line that those businesses which respond promptly to the CBI survey cannot be reporting what has happened in very much of month $t$ since they answer at the end of month $t-1$ or at the start/middle of month $t$.

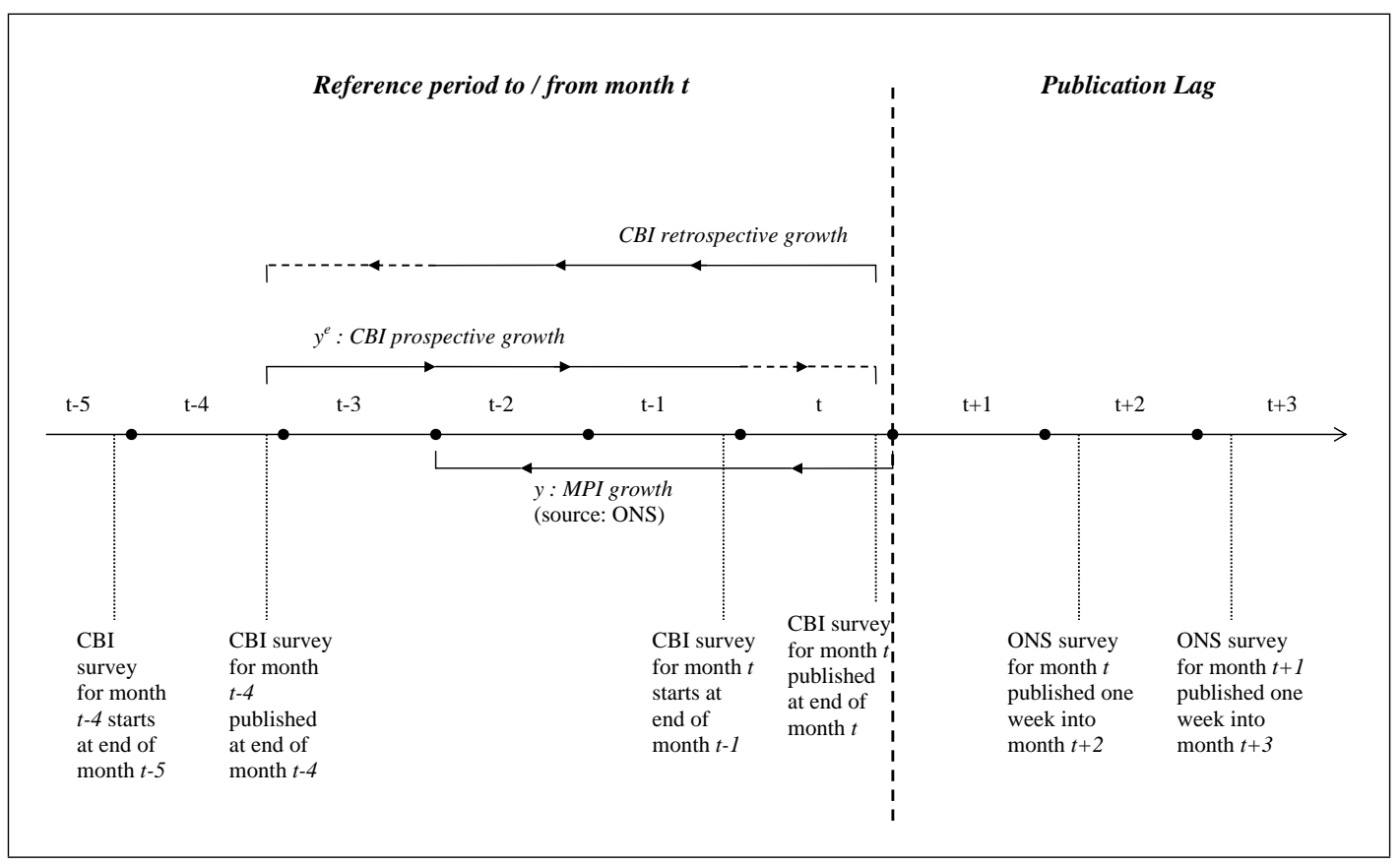

Figure 1: Time-line for the CBI's ITS (qualitative) and the ONS's MPI (quantitative) surveys. Until May 2003 the ITS asked firms about past and future movements over a four-month period (dashed line). Data collection for the CBI survey finishes about a week prior to publication.

As indicated in Section 1, we make comparisons between the indications firms give of their expectations of future output growth in the ITS and the subsequent output movements that they report in both the ITS and the MPI. When making this comparison, we relate the prospective qualitative data published at the end of month $(t-4)$ to the retrospective qualitative data published at the end of month $t$. As the left-hand-side of Figure 1 shows the prospective data published at month $(t-4)$ ask firms what they expect to happen over the period up to month $(t-1)$. Indeed, previously, given the change in the question, they were asked up to month $t$. Figure 1 indicates this change by using a dashed line to indicate the qualitative survey's reference period prior to May 
2003. But the retrospective data indicate what happened from month $t$ back to month $(t-3)$ or, with the question change, month $(t-4)$. So, as Figure 1 shows, there is at least a two month overlap between the retrospective and prospective survey data.

When making a comparison between what was reported to the ITS and to the MPI, as Figure 1 shows, we define MPI (quantitative) output growth over the interval $t$ to $(t-3)$. This ensures that when firms report their expectations (for the next three/four months) at the end of month $(t-4)$ they definitely do not know any of the quantitative outcome data (the outcome they are trying to forecast) $4_{4}^{4}$ Sample rotation and nonresponse means that, on average there are about 540 firms whose reported expectations can be compared with the outturns that the same firms report four months later.

The comparisons between the ITS and the MPI draw on a matched dataset which represents the intersection of those firms that respond to either survey. This group comprised about 170 firms each month, with a total of 807 firms over the period January 2000 to December 2004. This intersection has a bias towards large firms, because all large firms but only a sample of small firms are included in the MPI panel. We are, however, not greatly concerned about the non-representative nature of this group. First of all, there is no reason to suspect that the matched dataset picks up firms that are either particularly good or bad at forming expectations. And secondly, results on the information content of firms' expectations of output growth are of interest even if they do relate to a sample which is biased towards large firms. We refer the reader to Lui et al. (2010) for more details about the statistical properties of the matched dataset. As is common in micro-econometric studies, our analysis treats each observation equally and is not weighted to reflect the stratification of the sample.

\section{Notation}

Except where specifically indicated, all our variables relate to individual respondent, $i$ at time $t$. However, in most of the discussion it is not necessary to use subscripts to indicate the firm or period to which we are referring and we omit these subscripts. The summation operator, $\sum$, is applied across $i$, unless indicated otherwise. As Figure 1 also shows, $y$ denotes the output growth the firm experienced over the reference period

\footnotetext{
${ }^{4}$ To reflect the change to the ITS question in June 2003 we did try relating the prospective qualitative data published at the end of month $(t-4)$ to official MPI growth data measured up to month $(t-1)$ rather than month $t$. But our results were robust to measurement up to $(t-1)$ or $t$. This is consistent with serial correlation in the data and the view that firms do not interpret the CBI's question literally. A one-month change to a four month reporting window does not apper to affect the utility of the expectational data.
} 
$t-3$ to $t . y^{e}$ denotes the growth it had expected, at the end of month $(t-4)$, for this same period. But $y^{e}$ is latent. The CBI survey offers instead a qualitative indication of what the firm expected to happen over this reference period. At the end of month $(t-4)$ the firm reports a categorical expectation of what it expects to happen up to month $t$ (or month $(t-1)$ with the question change). This is represented by dummy variables $q_{j}^{e}$ where $j=1,2,3$ and $q_{1}^{e}=1$ if the firm expects an output decline, $q_{2}^{e}=1$ if no change is expected and $q_{3}^{e}=1$ if output is expected to rise. These categories are mutually exclusive and the dummies take the value 0 except when they take the value 1 . The CBI also offers a retrospective qualitative indication of the output growth the firm experienced over the reference period. $q_{j}(j=1,2,3)$ denotes the set of three categorical dummies representing the outcome that the firm retrospectively reported.

Formally

$$
q_{j}^{e}=1 \text { if } a_{j-1}<y^{e} \leq a_{j} ; 0 \text { otherwise and } q_{j}=1 \text { if } b_{j-1}<y \leq b_{j} ; 0 \text { otherwise }
$$

where $a_{j}, b_{j}$ are thresholds which can vary across firms and over time. As is standard we assume $a_{0}, b_{0}=-\infty$ and $a_{3}, b_{3}=\infty$. When these thresholds are unknown, as tends to be the case in most qualitative surveys, in constructing the rationality tests we assume, like Das et al. (1999), that $a_{j}=b_{j}$. But the thresholds can still differ across firms and over time. Without this assumption and, in the absence of quantitative information on these thresholds, it is impossible to compare the qualitative outcome and expectational data.

We then let $p_{j k}$ denote the conditional probability of a firm reporting outcome $j$ given it expected output growth to fall in category $k$ :

$$
p_{j k}=\operatorname{Pr}\left(q_{j}=1 \mid q_{k}^{e}=1\right) \geq 0 \text { with } \sum_{j} p_{j k}=1,(k=1,2,3)
$$

with a consistent estimator of $p_{j k}$, from a sample of $N$ firms, given as

$$
\hat{p}_{j k}=\frac{\sum q_{j} q_{k}^{e}}{\sum q_{k}^{e}} .
$$

The subsequent analysis ignores effects arising from the sample design of both the MPI and ITS.

\section{$5 \quad$ Nonparametric testing of qualitative survey data}

Tests of the best-case scenario are reported under the three distinct situations where firms report the category containing the mode, the median or the mean of their subjective 
density of future output growth. If the firm's loss function is asymmetric they may report the category that contains the $\alpha$-quantile instead. The tests based on the mode and median are constructed using the (retrospective and prospective) qualitative business survey data only. The tests based on the mean require knowledge of the quantitative outcome data and the thresholds. We also introduce a weaker test than rationality when firms have the mean of their subjective density in mind. This is a test of whether the expectational data contain any signal about the quantitative realisations data. We also suggest a means of testing what we call the "coherence" between the retrospective qualitative business survey data and the quantitative outcome data.

\subsection{Modal Expectations}

If firms base their categorical expectation $q_{k}^{e}$ on the mode of their subjective density forecast, then with rationality:

$$
p_{k k} \geq p_{j k}, j \neq k, \text { for all } k \text {. }
$$

The same condition for rationality is, in fact, also derived by Gourieroux \& Pradel (1986); although they assume that rather than reporting the mode, firms set their expectation to minimise squared error loss defined as $E\left\|q_{j}-q_{j}^{e}\right\|^{2}$.

For each $j \neq k$ separately, a test of the null hypothesis that $p_{k k}=p_{j k}$ versus the one-sided alternative $p_{k k}<p_{j k}$ can be constructed using

$$
\sqrt{n_{k}}\left(\frac{\left(\widehat{p}_{k k}-\widehat{p}_{j k}\right)}{\sqrt{2 \widehat{p}_{k k}}}\right) \rightarrow N(0,1)
$$

where $n_{k}=\sum q_{k}^{e}$. This follows, under the null, since under independence of $q_{j}$ across $i, \widehat{p}_{k k}\left(1-\widehat{p}_{k k}\right)$ is a consistent estimator of the variance of $\widehat{p}_{k k}$ and the covariances are $-\widehat{p}_{j k} \widehat{p}_{j^{\prime} k}\left(j \neq j^{\prime}\right)$.

\subsection{Median Expectations}

Consider the case where $y^{e}$ represents the median of the firm's subjective density forecast and the median falls in the $\left(a_{k-1}, a_{k}\right]$ interval so that the firm reports $q_{k}^{e}=1$. As Das et al. (1999) show, in fact $y^{e}$ could be assumed to represent the $\alpha$-quantile of a firm's subjective density forecast. For clarity of exposition we focus below on the case when $\alpha=0.5$. 
Under rationality $y$ is drawn from this same subjective density so that,

$$
\operatorname{Pr}\left(y-y^{e} \leq 0\right)=0.5
$$

In fact, rationality (i.e., equality of the subjective and objective density functions) is not required for (6) to hold since $\operatorname{Pr}\left(y-y^{e} \leq 0\right)=0.5$ is also satisfied under the weaker requirement that the objective density function for $y$ has median equal to $y^{e}$. But rationality is required for $\operatorname{Pr}\left(y-y^{e} \leq 0\right)=\alpha$, for all $\alpha$, when $y^{e}$ denotes the $\alpha$-quantile of the firm's subjective density forecast.

Since

$$
a_{k-1}<y^{e} \leq a_{k}
$$

it follows that,

$$
y-a_{k} \leq y-y^{e}<y-a_{k-1}
$$

With (6), it then follows that

$$
\begin{aligned}
\operatorname{Pr}\left(y-a_{k-1}\right. & \left.\leq 0 \mid q_{k}^{e}=1\right) \leq 0.5 \leq \operatorname{Pr}\left(y-a_{k} \leq 0 \mid q_{k}^{e}=1\right) \\
\operatorname{Pr}(y & \left.\leq a_{k-1} \mid q_{k}^{e}=1\right) \leq 0.5 \leq \operatorname{Pr}\left(y \leq a_{k} \mid q_{k}^{e}=1\right)
\end{aligned}
$$

which implies the following inequalities:

$$
\begin{aligned}
\sum_{j=k+1}^{3} p_{j k} & \leq 0.5,(k=1,2) \\
\sum_{j=1}^{k-1} p_{j k} & \leq 1-0.5,(k=2,3) .
\end{aligned}
$$

This means that for any group of firms that expect $q_{k}^{e}=1$, no more than half of the reported outcomes are in lower categories and no more than half are in higher categories.

Tests for whether (11) and (12) are satisfied for a given $k$ can then be constructed. For example, a test of (11) can be based on:

$$
\sqrt{n_{k}}\left(\sum_{j=k+1}^{3} \widehat{p}_{j k}-\sum_{j=k+1}^{3} p_{j k}\right) \rightarrow N\left[0,\left(1-\sum_{j=k+1}^{3} \hat{p}_{j k}\right) \sum_{j=k+1}^{3} \hat{p}_{j k}\right],(k=1,2) .
$$

Further to the analysis of Das et al. (1999), rather than undertake tests for each $k$ separately, a joint test can also be constructed. Under the best-case scenario, and importantly maintaining the assumption of no common/macroeconomic shocks, when firms expectations are based on the median, we should expect an equal proportion of firms to be positively and negatively surprised. Since $\sum_{k=1}^{2} \sum_{j=k+1}^{3} N^{-1} \sum q_{j} q_{k}^{e}$ is the 
proportion of firms (in the sample of $N$ firms) that report a higher outcome than they expected and $\sum_{k=2}^{3} \sum_{j=1}^{k-1} N^{-1} \sum q_{j} q_{k}^{e}$ is the proportion of firms that reported a lower outcome than expected, under the best-case scenario we should expect equality of these proportions (which are now unconditional, rather than conditional):

$$
\sum_{k=1}^{2} \sum_{j=k+1}^{3} N^{-1} \sum q_{j} q_{k}^{e}=\sum_{k=2}^{3} \sum_{j=1}^{k-1} N^{-1} \sum q_{j} q_{k}^{e}
$$

A $t$-test of (14) can again be constructed following (5), given that the proportions in (14), like those in (5), follow a binomial distribution.

\subsection{Mean Expectations}

\subsubsection{Testing the best-case scenario}

If firms report the category that contains the mean of their subjective distribution, which corresponds to them minimising squared forecast errors, under rationality:

$$
E\left(y \mid q_{k}^{e}=1\right) \in\left(a_{k-1}, a_{k}\right]
$$

The best-case scenario then implies that for any group of firms who expect $q_{k}^{e}=1$ the mean of the distribution of (quantitative) outcomes falls in category $k$. To implement a test of (15) requires both data on the quantitative outcomes $y$ and knowledge of the thresholds $a_{k}$. Even when the $a_{k}$ are unknown (15) implies that $E\left(y \mid q_{k}^{e}=1\right)$ should increase with $k$, as long as the thresholds increase in $k$. Typically the $a_{k}$ are unknown. For example, in the cross-country qualitative business survey held by the European Commission the $a_{k}$ are determined subjectively and not reported by the survey.

\subsubsection{Testing signal versus noise}

In the absence of knowledge of the thresholds a test for the best-case scenario cannot be constructed. We therefore introduce a weaker test of whether the expectational data contain any signal, which might be useful to forecasters, about the quantitative outcome data. Again this assumes firm's have the mean of their subjective density in mind. This test follows from the observation that if $E\left(y \mid q_{k}^{e}=1\right)$ does not increase with $k$ the expectational data are simply "noise".

Let $\bar{y}_{j k}$ denote the mean (across firms) quantitative outcome for $y$ given qualitative outcome $j$ and qualitative expectation $k$. The variance of these sample means can also be computed in a straightforward manner assuming independence of $y$; these variance estimates facilitate construction of the ensuing statistical tests. The Winsorised variance 
is the usual sample variance based on the Winsorised values. As (15) indicates, the expectational data contain a signal about the quantitative outcome data when

$$
\left(\bar{y}_{11}+\bar{y}_{21}+\bar{y}_{31}\right) \leq\left(\bar{y}_{12}+\bar{y}_{22}+\bar{y}_{32}\right) \leq\left(\bar{y}_{13}+\bar{y}_{23}+\bar{y}_{33}\right)
$$

and are simply noise when

$$
H_{0}:\left(\bar{y}_{11}+\bar{y}_{21}+\bar{y}_{31}\right)=\left(\bar{y}_{12}+\bar{y}_{22}+\bar{y}_{32}\right)=\left(\bar{y}_{13}+\bar{y}_{23}+\bar{y}_{33}\right) .
$$

Pairwise $t$-tests for 17) can be constructed for the difference between any two of the three sample means. The required variance estimates can be readily computed since the sample means for each categorical response are based on disjoint sets of observations. Independence means the variance estimate for the difference is simply the sum of the individual variances. To control the joint size of the three possible pairwise tests would require the use of a stricter $p$-value. The Bonferroni correction indicates a $p$-value threshold, for a $95 \%$ confidence level, of $(100 \%-95 \%) / 3=1.6 \%$ rather than $5 \%$.

\subsubsection{Testing coherence}

Coherence between the qualitative and quantitative outcome data requires that in the qualitative survey firms retrospectively report the category that contains the quantitative outcome, drawn from their objective (but unknown) density:

$$
E\left(y \mid q_{k}=1\right) \in\left(b_{k-1}, b_{k}\right]
$$

implying that $E\left(y \mid q_{k}=1\right)$ should also increase with $k$. This will hold even when the thresholds used in (18) differ from those in (15).

Similarly, and related to (15), if $E\left(y \mid q_{k}=1\right)$ does not increase with $k$ one might classify the qualitative outcome data as containing no signal about the subsequent quantitative outcome data: they are simply noise. The null hypothesis that the retrospective qualitative survey data are noise then is:

$$
H_{0}:\left(\bar{y}_{11}+\bar{y}_{12}+\bar{y}_{13}\right)=\left(\bar{y}_{21}+\bar{y}_{22}+\bar{y}_{23}\right)=\left(\bar{y}_{31}+\bar{y}_{32}+\bar{y}_{33}\right) .
$$

\section{$6 \quad$ Results}

\subsection{Modal Expectations}

Figure 2 plots, across time, the proportion of firms that replied 'up', 'same' or 'down' to the retrospective question in the qualitative business survey at time $t$ given that they 
were previously pessimistic (expected a fall), expected no change or optimistic (expected a rise) according to the prospective question from the qualitative business survey at time $(t-4)$. It shows that the modality condition (4) is satisfied for most months. There are 6 violations of the inequality (4), all in 2004, when firms were pessimistic. There is a just one violation for those firms that expected no change, and 5 violations for optimistic firms. We also note that only one of these violations, of the best-case scenario, is statistically significant at a (one-sided) 95\% level and that is in October 2003, when firms were optimistic. As discussed above, to control the joint size of sequential $t$-tests like these requires the use of a smaller significance level. But by continuing to conduct our tests at the $5 \%$ significance level we are likely to be over-rejecting, and therefore if anything biasing our results against the best-case scenario. Our conservative tests can therefore be interpreted as providing evidence that firms' expectations satisfy the best-case scenario.

Further evidence in support of the best-case scenario is seen when one pools, across time, the estimates in Figure 2. The mean (across $t$ ) percentages reveal that for the pessimistic firms $\widehat{p}_{11}=54.7 \%$ which is greater than both $\widehat{p}_{21}$ at $34.3 \%$ and $\widehat{p}_{31}$ at $11.0 \%$. Similarly for the firms expecting no-change, $\widehat{p}_{22}=48.7 \%$ which is greater than $\widehat{p}_{12}$ at $28.6 \%$ and $\widehat{p}_{32}$ at $22.7 \%$. And for the optimists $\widehat{p}_{33}=47.3 \%$ which is greater than $\widehat{p}_{13}$ at $17.9 \%$ and $\widehat{p}_{23}$ at $34.9 \%$. Firms' expectations therefore satisfy the bounds 4 and are consistent with the best-case scenario. But additional to Das et al. (1999), as we also see from Figure 2, this is not saying that the expectational data are necessarily that useful or reliable. This is since, on average across time, $45 \%$ of firms who expected a 'down' did not subsequently report a 'down'; $51 \%$ of firms who expected 'no change' did not subsequently report 'no change'; and, $52 \%$ of firms who expected an 'increase' did not subsequently report an 'increase'. The best-case scenario appears quite a weak requirement. It remains important to evaluate the qualitative data against the quantitative data.

\subsection{Median Expectations}

Since this test exploits the ordering of firms' responses, unlike (4), the requirements for the best-case scenario are stronger under the median response. It implies sharper bounds given that (11) implies (4) for $k=1$ (the lowest category) and (12) implies (4) for $k=3$ (the highest category). This means that the median category assumption requires a majority of firms to be in the expected bin when firms are either optimistic 
or pessimistic, while the modal category assumption requires only a plurality (i.e., the highest number of firms, but not necessarily a majority).

Figure 3 presents (two-sided) $90 \%$ confidence intervals for the probabilities in (11) and (12). Looking first at the top left panel for the pessimists we see that only for 6 months, towards the end of the sample period, do the confidence bands rise above 0.5 such that we reject (11) with a one-sided test with significance level $5 \%$. These rejections suggest that firms may have had a quantile lower than the $50 \%$ associated with the median in mind. The bottom panels of Figure 3 show that for those firms that expected 'no change', since the bands are below 0.5 , one cannot reject (11) or (12). The top right panel, for the optimists, shows that on 12 occasions the confidence bands rise above 0.5. This now suggests, if we believe firms are rational, that they may have set their qualitative point expectation with a quantile of their subjective density higher than the $50 \%$ associated with the median in mind. This would be consistent with the view that firms are more afraid of under-predicting than over-predicting the future values of $y$. But for most of the sample-period the requirements for the best-case scenario are met under the median response.

Figure 4 then provides complementary information on the balances of risks to firms. It plots both the proportion of firms that reported a higher outcome than they expected and the proportion that reported a lower outcome than expected. Recall that under the best-case scenario, when firms have the median in mind, we should expect equality of these two proportions. But Figure 4 shows that, for much of the sample-period, firms were too optimistic when reporting their expectations with output growth turning out lower than expected. Or firms reported their qualitative point expectation with a quantile of their subjective density forecast higher than the median in mind. But the middle panel of Figure 4, which plots $t$-values for (14), indicates that the differences between these two proportions are statistically insignificant at $10 \%$ (two-sided tests) for most of the sample period. This further supports the view that, when firms reply with the median of their subjective density forecast in mind, the firm-level qualitative expectational data were best-case predictions. Finally, the bottom panel of Figure 4 shows that any tendency for firms to be too optimistic, when setting their expectations, does not relate to movements in the aggregate economy, as characterised by the growth rate of (aggregate) industrial production. The $R^{2}$ between the proportion of overly optimistic firms and industrial production growth is 0.06 , which is statistically insignificant at a $5 \%$ level 5

\footnotetext{
${ }^{5}$ The sharp transitory movement in industrial production seen in mid 2002 was associated with seasonal adjustment difficulties in May 2002. A Bank Holiday was moved to the first week of June and
} 


\subsection{Mean Expectations}

To examine (15) and (17), and test for coherence between the two datasets, (19), requires use of the matched dataset, discussed in Section 3. The sample-size of the ITS drops considerably when matched against the MPI and this precludes meaningful analysis across time, as above. We will therefore focus on results pooled across time and simply remark that, no doubt explained in part by the smaller sample sizes, there was considerable volatility across time in terms of the relationship between the two datasets.

Table 1 presents estimates of the sample mean of the quantitative outturns, $y$, pooled across firms and time, given both the firms' retrospective and prospective qualitative responses, prior to Winsorisation. The table also reports $t$-values, testing the statistical significance of these mean estimates. The number of available observations is also reported. Table 2 then reports analogous results when $y$ is Winsorised to mitigate the effect of outliers. In these tables the weighted (by the number of observations) sum of the sample means across a given row (or column) gives the sample mean of $y$ for each retrospective (or prospective) categorical response.

Inspection of these row and column sums indicates that only retrospectively do the sample means increase with $j$. We should expect them to increase if the retrospective qualitative business data are "coherent" with the quantitative outturns. Looking first at the raw data in Table 1, when firms retrospectively reported a 'down' in fact they contracted, on average, as revealed by the quantitative data, by $-4.0 \%$. When they reported an 'up' they grew by $2.7 \%$. And when they reported 'no-change' they contracted very slightly $(-0.1 \%)$. But one cannot reject the null hypothesis that in fact output growth was zero even at a $1 \%$ significance level, with a $t$-ratio of -0.145 . Even assuming all firms have the same thresholds, further assumptions about the objective density for $y$ would be needed before inference about the sign of the thresholds, $b_{1}$ and $b_{2}$, could be drawn from the results in Table 1 alone.

Carrying out pairwise $t$-tests to test $(19)$ also reveals these differences between the sample means to be statistically significant at a $5 \%$ significance level. In particular, the $t$-value testing equality of the sample means for those firms reporting a 'down' and an 'up' is 3.90 (implying a 1-sided $p$-value of $0.0 \%$ ). There remain pronounced differences between the sample means of those firms reporting a 'down' or an 'up' when

there was an additional holiday to celebrate the Queen's Jubilee. The 2002 (Football) World Cup is also believed to have distorted the typical seasonal pattern. In any case, this oddity in the industrial production data does not affect our analysis below which is based on the underlying firm-level data. The aggregate data are considered only for reference purposes. 
compared with those firms reporting 'no-change'. The associated $t$-values are 2.56 and 1.87 , respectively, implying (1-sided) $p$-values of $0.5 \%$ and $3 \%$. This also implies rejection of the joint null hypothesis in (19), after applying the Bonferroni correction. Therefore, overall the retrospective survey data do contain a signal about the quantitative data. A similar picture is seen using the Winsorised data in Table 2, although the sample means do not increase so strongly with $j$.

But the expectational survey data do not contain a statistically significant signal about the quantitative outturns, $y$. Firms that expected a 'down' did, on average, in fact subsequently contract, as revealed by the quantitative data, but only by $-1.0 \%$ as seen in Table 1, and $-0.67 \%$ as shown in Table 2. This contrasts with the much larger contractions (of $-4.0 \%$ and $-3.1 \%$ ) in firms that reported 'a down' retrospectively. In turn, firms that expected an 'up' did subsequently grow, but again quite modestly at $1.4 \%$ and $0.34 \%$ in Tables 1 and 2 , respectively. These sample means, for the expectational data, are also poorly determined (with large standard errors) such that one cannot reject the null hypothesis of noise, (17), using information contained in both Tables 1 and 2. For example, focusing on the (pairwise) test of equality of the sample means for those firms that expected a 'down' and those that expected an 'up' we find $t$-values in Tables 1 and 2 of 1.27 and 0.84 , respectively.

Macroeconomic shocks, occurring after the forecast was made, might be thought to contribute to our finding that the expectational data do not contain a signal about the subsequent quantitative outturns; although they do not appear to prevent the expectational data being best-case predictions for the qualitative outcome data, as shown in Sections 6.1 and 6.2. We did re-compute Tables 1 and 2 having subtracted macroeconomic forecasts, based on recursive estimation of an autoregressive model estimated using real-time data vintages available from the ONS, from $y$ and inference was qualitatively unchanged. This is unsurprising, given the absence (see Figure 4) of pronounced (aggregate) cyclical movements in this stable sample. The ex post macroeconomic forecasting errors observed over this sample period average out to zero.

\subsection{An apparent paradox}

To summarise, our analysis of the firm-level qualitative and quantitative data has revealed that:

i.) the firm-level qualitative expectational data are best-case predictions of the outcomes but, importantly, the 'outcomes' as declared qualitatively by firms; 
ii.) the retrospective qualitative data and the quantitative outcome data from the two different surveys are coherent with each other;

iii.) the qualitative expectational data are not consistent with what we should expect if they were best-case predictions of the quantitative outturns; they do not even contain a signal about the quantitative outcome data.

This is an apparent paradox. Given i.) and ii.) hold we might expect this to imply that the qualitative expectational data should be useful at explaining the quantitative outcome data, contradicting our finding in iii.). While of empirical significance, we explore two possible explanations for this apparent paradox.

Firstly, the accumulation of 'forecasting' errors and 'discretisation' errors mean the ability of the qualitative expectational data to predict the quantitative outcome data can be drowned out by the combination of these two noise terms. This can be seen by defining the two errors as follows:

$$
\begin{aligned}
E(y \quad & \left.\mid \quad q_{k}=1\right)=E\left(y \mid q_{k}^{e}=1\right)+u_{k} \\
y & =E\left(y \mid q_{k}=1\right)+u_{k}^{d}
\end{aligned}
$$

where the 'forecasting' error, $u_{k}$, defined in (20), is the difference between firms' retrospective qualitative assessment of their output growth and firms' qualitative forecast and reflects how firms' update their (qualitative) forecast having observed $y$. The 'discretisation' error, $u_{k}^{d}$, is the difference between the outcome, $y$, and firms' qualitative assessment of it. Assuming a normal distribution for $y$ this can be written like a generalised residual (see Gourieroux et al. (1987)) so that ${ }^{6}$

$$
u_{k}^{d}=y-\frac{\phi\left(a_{k-1}\right)-\phi\left(a_{k}\right)}{\Phi\left(a_{k}\right)-\Phi\left(a_{k-1}\right)}
$$

where $\phi($.$) denotes the density and \Phi($.$) the distribution function of the standard normal$ distribution. $u_{k}^{d}$ reflects how much information is lost through firms reporting $q_{k}$ rather than $y$. Discretisation of (the continuous) $y$ reduces the amount of information in the sense defined by Shannon (1948). Less information would be lost if the number of states

\footnotetext{
${ }^{6}$ The normality assumption is innocuous given our use of nonparametric tests. We make it here for expositional purposes only. The point we wish to make is that an error is induced, and information lost, when then the quantitative data are reduced to a qualitative response. A different distributional assumption for $y$ would affect the form $u_{k}^{d}$ takes but not eliminate it.
} 
into which $y$ was discretised was greater than three $(k=1,2,3)$. Substituting 20 into (21) then reveals that

$$
y=E\left(y \mid q_{k}^{e}=1\right)+u_{k}+u_{k}^{d}
$$

implying that the informational content of firms' qualitative expectations is weakened by the compounding of the two errors..$^{7}$

Our results therefore provide firm-level motivation for the method introduced by Lee (1994) to account for this discretisation error when using expectational data at the aggregated/macroeconomic level. Lee (1994) finds that the evidence against the rationality of aggregated expectational data, from the CBI survey, is weaker when one conducts rationality tests based on $u_{k}$ (aggregated across firms) alone, rather than using the composite error $\left(u_{k}^{d}+u_{k}\right)$. Similarly, we find that adding the discretisation error to the forecasting error renders the qualitative expectational data uninformative about the quantitative outcome data at the firm-level.

Secondly, firms may not reply to the expectational question with the conditional mean $E\left(y \mid q_{k}^{e}=1\right)$ of their subjective density forecast in mind. They may use the mode or median instead. When they form best-case predictions in this manner i.) should hold. But the qualitative expectational data need not be best-case predictions of the quantitative outturns and need not contain a signal about them - as long as the mean forecast does differ from the mode/median. They will differ when there are pronounced asymmetries/multi-modalities in firms' conditional density forecasts. But ii.) should continue to hold given that retrospectively firms do not base their qualitative response on their subjective density forecast. Instead they are supposedly replying by stating the category $q_{k}=1(k=1,2,3)$ in which $y$ is contained.

From a practical perspective these results suggest that qualitative business survey data, given that they are published ahead of the ONS's quantitative data, are likely to prove more useful for nowcasting than forecasting. But it is possible that aggregation of firm-level expectational data improves the informational content of macroeconomic indicators constructed from these expectational data. Forecasting and discretisation errors may be offsetting. Certainly, as argued by Mitchell et al. (2005), more attention should be devoted to how qualitative expectational data are quantified and aggregated. The widely used "balance of opinion" is but one option. Nevertheless, it would have been reassuring for those using the aggregated expectational data if we had found that the

\footnotetext{
${ }^{7}$ Rationality requires the discretisation error, $u_{k}^{d}$, and $u_{k}$ to be mean zero and serially uncorrelated, and orthogonal to information known at the time the firm formed its expectation.
} 
firm-level expectational data contained a signal about the quantitative outcome data.

\section{Conclusion}

Qualitative expectational data from business surveys are widely used to construct forecasts on the assumption that they are forward-looking and say something useful about what will happen to the economy in the future. But, based typically on evaluation at the macroeconomic level, doubts persist about the utility of these data. In this paper we evaluate the ability of the underlying firm-level expectations to anticipate subsequent outcomes. Importantly this evaluation is not hampered by only having access to qualitative outcome data obtained from subsequent business surveys. Quantitative outcome data from official surveys are also exploited. This required access to a panel dataset, for UK manufacturing firms, which matches firms' responses from the qualitative business survey with these same firms' quantitative replies to a different survey carried out by the national statistical office.

We use and develop nonparametric tests for the rationality of the firm-level qualitative expectational data. Rationality tests remain a useful tool in evaluating the utility of expectational data. This is because under rationality outcomes do not differ systematically from what was expected. But to test the rationality of qualitative expectations data requires auxiliary assumptions to be made, which are tested jointly with rationality. We therefore follow Manski (1990) and Das et al. (1999) and refer to the tests as tests of the "best-case scenario". In particular, we discuss how the implications of rationality depend on the firm's loss function. Under rationality, different loss functions result in different categorical predictions, given the firm's subjective density forecast. We therefore follow Das et al. (1999) and conduct tests when firms report the mode, the median (more generally the alpha-quantile) or the mean of their subjective density forecast of future output growth. When firms have the mode or median of their subjective density in mind, tests of the best-case scenario exploit the (retrospective and prospective) qualitative business survey data only. But when they have the mean in mind, tests require knowledge of the quantitative outcome data.

As well as testing the ability of the expectational data to forecast the two distinct outcome variables, we test what we call the coherence between these qualitative and quantitative outcome measures. This involves testing whether the two outcome variables are measuring the same concept of output growth, as implicitly assumed when outcome data from qualitative business surveys are used to provide a contemporaneous indication 
(nowcast) of economic activity.

The tests reveal an apparent paradox. Despite evidence that the qualitative and quantitative outcome data are coherent, we find that the expectational data offer rational forecasts of the qualitative but not the quantitative outcomes. One explanation is that firms do not reply to the expectational question with the conditional mean of their subjective density forecast in mind. Another candidate explanation is that 'discretisation' errors, explained by the qualitative nature of the expectational data, drown out the ability of the expectational data to predict the quantitative outcome data.

In summary, our firm-level findings therefore suggest that:

1. Qualitative business surveys are likely to prove more useful for nowcasting than forecasting.

2. Business surveys might be of more value for forecasting if the questions in the survey were modified to ask for quantitative expectational data.

(a) It would also help if the survey were explicit about what 'feature' of their subjective density forecast firms should report. At present some may report subjective means, others modes or medians. Indeed if their loss function is asymmetric they may report various quantiles. We have seen that the feature reported can affect the utility of the survey.

(b) But ideally business surveys would ask for probabilistic information in the form of a density forecast. Some surveys of professional forecasters already supply this information, as discussed above. Forecasts can then be used compared and evaluated - independently of firms' loss functions; see Diebold et al. (1998) and Mitchell \& Wallis (2010). Point forecasts also reveal nothing about the uncertainty that firms feel. Comparisons can also be made between the point forecasts and the subjective density forecasts; see Engelberg et al. (2009) and Clements (2009, 2010).

Future work might test the utility of expectational data at the firm-level both for different sectors and for other countries using the methods we set out. This may require the permission of the survey producers. As in the UK, the qualitative and quantitative surveys are often carried out by different institutions. But further applications at the firm-level would be helpful in establishing whether or not our results, for UK manufacturing, are shared by expectational data more generally. 


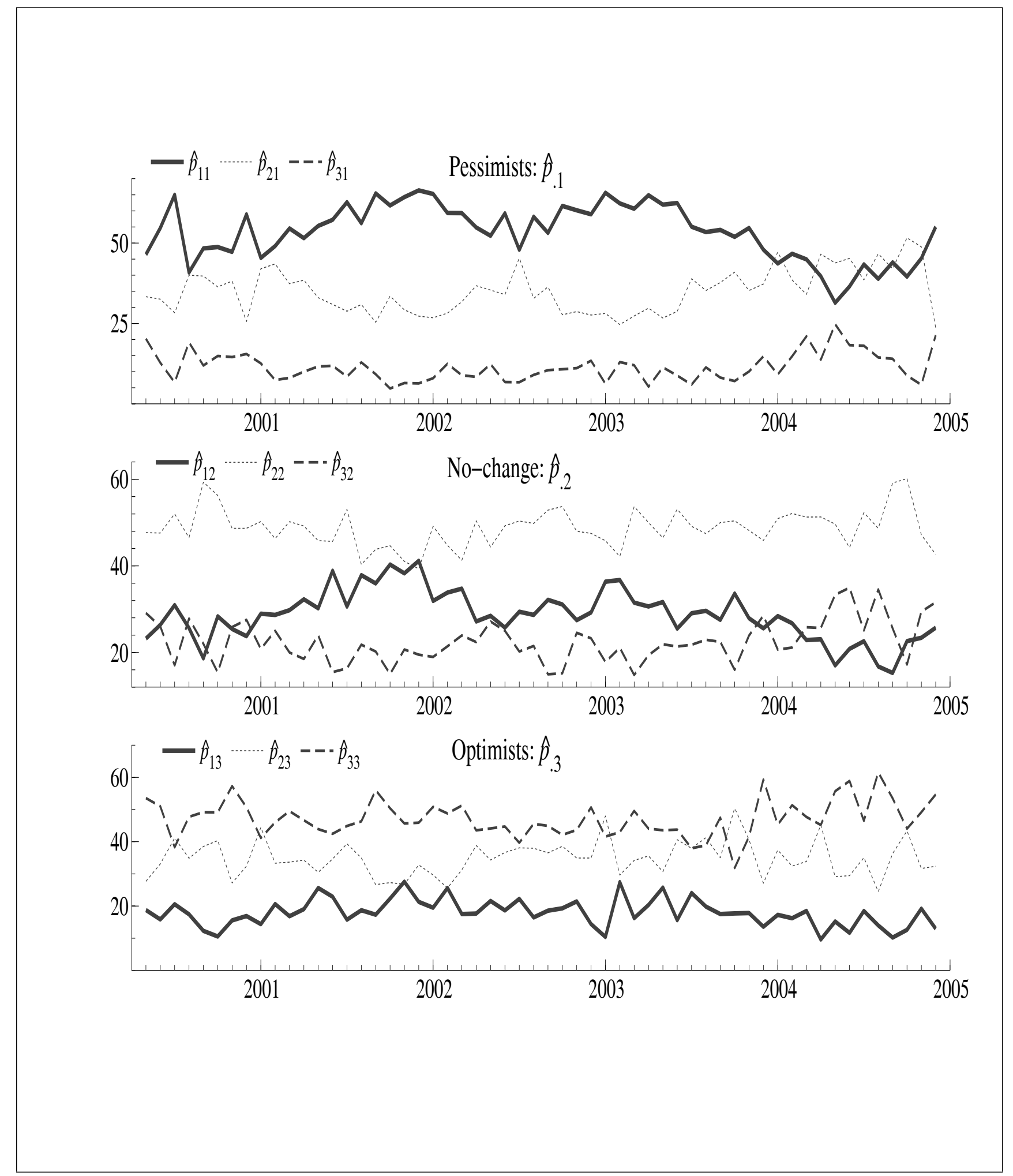

Figure 2: Estimates of $p_{j k}=\operatorname{Pr}\left(q_{j}=1 \mid q_{k}^{e}=1\right.$ ) (in percentages), where $j, k=1,2,3$ denote down, same and up, respectively. 


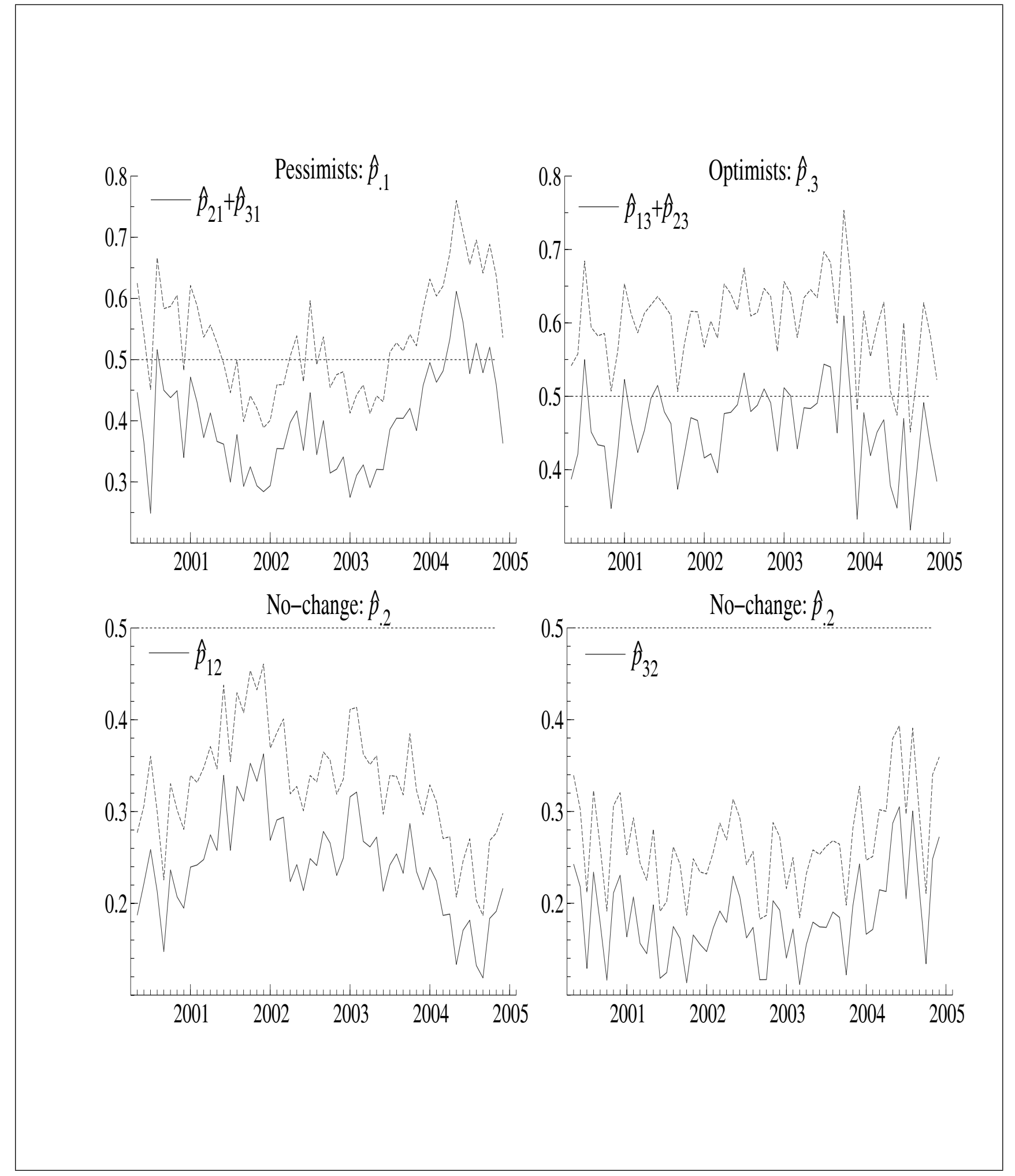

Figure 3: 90\% confidence intervals for the cumulative probabilities ( 11 ) and (12) used to test median expectations 

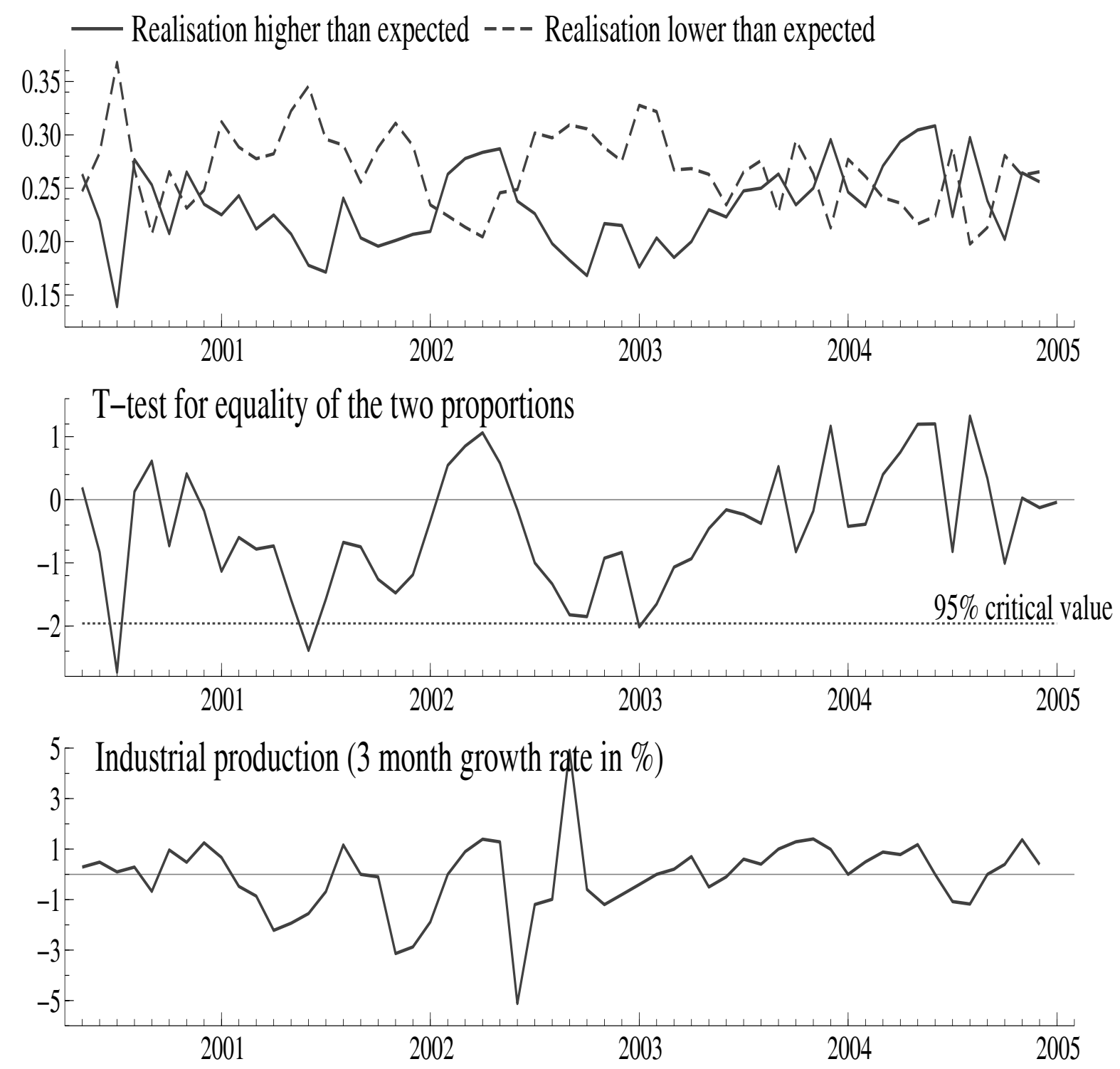

Figure 4: The top panel shows the proportion of firms who, when looking at the median of their predictive density, were too optimistic or too pessimistic when forecasting. The middle panel reports $t$-tests for the equality of these two proportions based on (14). The bottom panel shows the growth rate of (aggregate) industrial production. 
Table 1: Sample mean of the quantitative outturns in \% (raw data), y, pooled across firms and time, given the firms' retrospective and prospective qualitative responses from the business survey. $j, k=1,2,3$ denote down, same and up, respectively

\begin{tabular}{|c|c|c|c|c|c|}
\hline & $j / k$ & 1 & $\begin{array}{r}q_{k}^{\llcorner}= \\
2\end{array}$ & 3 & Retrospective Responses Sum \\
\hline \multirow{3}{*}{$q_{j}=1$} & 1 & $\begin{array}{c}-2.689 \\
(-1.286) \\
\{528\}\end{array}$ & $\begin{array}{c}-4.790 \\
(-2.757) \\
\{586\}\end{array}$ & $\begin{array}{c}-5.401 \\
(-2.157) \\
\{190\}\end{array}$ & $\begin{array}{c}-4.028 \\
(-3.312) \\
\{1304\}\end{array}$ \\
\hline & 2 & $\underset{\substack{(.9 .976) \\
\{387\}}}{2.304}$ & $\begin{array}{c}-0.946 \\
(-0.836) \\
\{1274\}\end{array}$ & $\begin{array}{c}0.091 \\
(0.045) \\
\{417\}\end{array}$ & 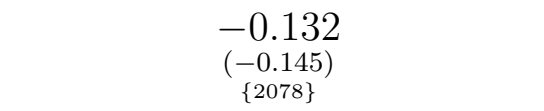 \\
\hline & 3 & $\begin{array}{c}-4.087 \\
(-1.127) \\
\{127\}\end{array}$ & $\begin{array}{c}2.414 \\
(1.314) \\
\{549\}\end{array}$ & $\begin{array}{c}4.444 \\
(2.389) \\
\{612\}\end{array}$ & $\begin{array}{l}2.738 \\
(2.217) \\
\{1288\}\end{array}$ \\
\hline Prospective Responses Sum & & $\frac{-1.005}{(-0.690)}$ & $\begin{array}{c}-1.115 \\
(-1.320) \\
\{2409\}\end{array}$ & $\begin{array}{l}1.420 \\
(1.155) \\
\{1219\}\end{array}$ & \\
\hline
\end{tabular}

Notes: $t$-values in (.), and the number of observations in \{\} . 
Table 2: Sample mean of the quantitative outturns in \% (Winsorised data), $y$, pooled across firms and time, given the firms' retrospective and prospective qualitative responses from the business survey. $j, k=1,2,3$ denote down, same and up, respectively

\begin{tabular}{|c|c|c|c|c|c|}
\hline \multirow{2}{*}{\multicolumn{2}{|c|}{$j / k$}} & \multicolumn{3}{|c|}{$q_{k}^{e}=1$} & \multirow[b]{2}{*}{ Retrospective Responses Sum } \\
\hline & & 1 & 2 & 3 & \\
\hline \multirow{3}{*}{$q_{j}=1$} & 1 & $\begin{array}{c}-2.211 \\
(-1.729) \\
\{528\}\end{array}$ & $\begin{array}{c}-3.239 \\
\left(\begin{array}{c}-2.807) \\
\{586\}\end{array}\right.\end{array}$ & $\begin{array}{c}-5.298 \\
(-2.652) \\
\{190\}\end{array}$ & $\begin{array}{c}-3.123 \\
(-3.961) \\
\{1304\}\end{array}$ \\
\hline & 2 & $\begin{array}{c}1.608 \\
(1.158) \\
\{387\}\end{array}$ & $\begin{array}{c}-0.275 \\
(-0.373) \\
\{1274\}\end{array}$ & $\begin{array}{c}0.135 \\
(0.103) \\
\{417\}\end{array}$ & $\begin{array}{l}0.158 \\
(0.271) \\
\{2078\}\end{array}$ \\
\hline & 3 & $\begin{array}{c}-1.224 \\
(-0.450) \\
\{127\}\end{array}$ & $\begin{array}{c}1.016 \\
(0.848) \\
\{549\}\end{array}$ & $\begin{array}{c}2.232 \\
(1.905) \\
\{612\}\end{array}$ & $\begin{array}{l}1.373 \\
(1.712) \\
\{1288\}\end{array}$ \\
\hline Prospective Responses Sum & & $\begin{array}{c}-0.672 \\
(-0.753) \\
\{1042\}\end{array}$ & $\begin{array}{c}-0.701 \\
(-1.268) \\
\{2409\}\end{array}$ & $\begin{array}{l}0.341 \\
(0.424) \\
\{1219\}\end{array}$ & \\
\hline
\end{tabular}

Notes: $t$-values in (.), and the number of observations in \{\} . 


\section{References}

Abberger, K. (2007), 'Qualitative business surveys and the assessment of employment a case study for germany', International Journal of Forecasting 23(2), 249-258.

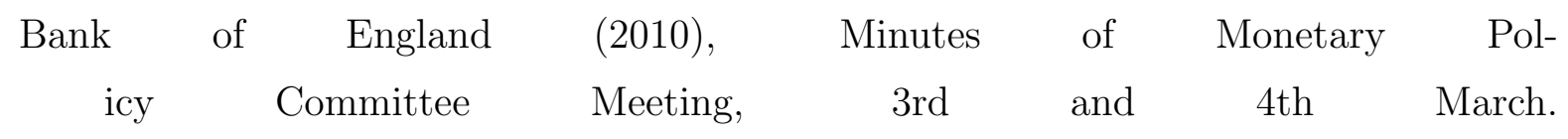
www.bankofengland.co.uk/publications/minutes/mpc/pdf/2010/mpc1003.pdf.

Bertrand, M. \& Mullainathan, S. (2001), 'Do people mean what they say? Implications for subjective survey data', American Economic Review 91(2), 67-72.

Bonham, C. S. \& Cohen, R. H. (2001), 'To aggregate, pool, or neither: Testing the rational-expectations hypothesis using survey data', Journal of Business 85 Economic Statistics 19(3), 278-91.

Branch, W. A. (2004), 'The theory of rationally heterogeneous expectations: evidence from survey data on inflation expectations', Economic Journal 114, 592-621.

Brown, B. W. \& Maital, S. (1981), 'What do economists know? an empirical study of experts' expectations', Econometrica 49(2), 491-504.

Carlson, J. \& Parkin, M. (1975), 'Inflation expectations', Economica 42, 123-138.

Carroll, C. D., Fuhrer, J. C. \& Wilcox, D. W. (1994), 'Does consumer sentiment forecast household spending? if so, why?', American Economic Review 84(5), 1397-1408.

Claveria, O., Pons, E. \& Ramos, R. (2007), 'Business and consumer expectations and macroeconomic forecasts', International Journal of Forecasting 23(1), 47-69.

Clements, M. P. (2009), Internal consistency of survey respondents' forecasts: Evidence based on the Survey of Professional Forecasters, in J. L. Castle \& N. Shephard, eds, 'The Methodology and Practice of Econometrics. A Festschrift in Honour of David F. Hendry. Chapter 8', Oxford University Press, Oxford, pp. 206-226.

Clements, M. P. (2010), 'Explanations of the inconsistencies in survey respondents' forecasts', European Economic Review 54(4), 536-549.

Clements, M. P. \& Hendry, D. F. (1998), Forecasting Economic Time Series, Cambridge University Press: Cambridge. 
Das, M., Dominitz, J. \& van Soest, A. (1999), 'Comparing predictions and outcomes: Theory and application to income changes', Journal of the American Statistical Association 94, 75-85.

Diebold, F. X., Gunther, A. \& Tay, K. (1998), 'Evaluating density forecasts with application to financial risk management', International Economic Review 39, 863-883.

Dixon, W. (1960), 'Simplified estimation from censored normal samples', Annals of Mathematical Statistics 31, 385-391.

Driver, C. \& Urga, G. (2004), 'Transforming qualitative survey data: performance comparisons for the UK', Oxford Bulletin of Economics and Statistics 66, 71-90.

Easaw, J. Z. \& Heravi, S. M. (2004), 'Evaluating consumer sentiments as predictors of UK household consumption behavior: Are they accurate and useful?', International Journal of Forecasting 20(4), 671-681.

Engelberg, J., Manski, C. F. \& Williams, J. (2009), 'Comparing the point predictions and subjective probability distributions of professional forecasters', Journal of Business and Economic Statistics 27, 30-41.

Forni, M., Hallin, M., Lippi, M. \& Reichlin, L. (2001), 'Coincident and leading indicators for the euro area', Economic Journal 111(471), 62-85.

Gourieroux, C., Monfort, A., Renault, E. \& Trognon, A. (1987), 'Generalized residuals', Journal of Econometrics 34, 5-32.

Gourieroux, C. \& Pradel, J. (1986), 'Direct test of the rational expectation hypothesis', European Economic Review 30(2), 265-284.

Hall, S. \& Mitchell, J. (2009), Recent developments in density forecasting, in T. Mills and K. Patterson, ed., 'Handbook of Econometrics: Vol. II', Palgrave, pp. 199-239.

Hansson, J., Jansson, P. \& Lof, M. (2005), 'Business survey data: Do they help in forecasting gdp growth?', International Journal of Forecasting 21(2), 377-389.

Horvath, B., Nerlove, M. \& Wilson, D. (1992), A re-interpretation of direct tests of forecast rationality using business survey data, in K. H. Oppenlander \& G. Poser, eds, 'Business Cycle Analysis by Means of Economic Surveys, Part 1', Avebury, Aldershot. 
Ivaldi, M. (1992), 'Survey evidence on the rationality of expectations', Journal of Applied Econometrics 7(3), 225-41.

Kauppi, E., Lassila, J. \& Terasvirta, T. (1996), 'Short-term forecasting of industrial production with business survey data: experience from finland's great depression 1990-1993', International Journal of Forecasting 12(3), 373 - 381.

Keane, M. P. \& Runkle, D. E. (1990), 'Testing the rationality of price forecasts: New evidence from panel data', American Economic Review 80(4), 714-35.

Lee, K. (1994), 'Formation of Price and Cost Inflation Expectations in British Manufacturing: a Multisectoral Analysis', Economic Journal 104, 372-386.

Lui, S., Mitchell, J. \& Weale, M. (2010), 'Qualitative business surveys: Signal or noise?', Journal of the Royal Statistical Society, Series A . Forthcoming. Available as NIESR discussion paper no. 323.

Manski, C. (1990), 'The use of intentions data to predict behavior: A best case analysis', Journal of the American Statistical Association 85, 934-940.

Matheson, T. D., Mitchell, J. \& Silverstone, B. (2010), 'Nowcasting and predicting data revisions using panel survey data', Journal of Forecasting 29(3), 313-330.

McIntosh, J., Schiantarelli, F. \& Low, W. (1989), 'A qualitative response analysis of uk firms' employment and output decisions', Journal of Applied Econometrics 4, 251264.

Mitchell, J., Smith, R. \& Weale, M. (2005), 'Forecasting manufacturing output growth using firm-level survey data', The Manchester School 73, 479-499.

Mitchell, J. \& Wallis, K. F. (2010), 'Evaluating density forecasts: Forecast combinations, model mixtures, calibration and sharpness', Journal of Applied Econometrics . Forthcoming.

Nerlove, M. (1983), 'Expectations, plans, and realizations in theory and practice', Econometrica 51(5), 1251-79.

Patton, A. J. \& Timmermann, A. (2007a), 'Properties of optimal forecasts under asymmetric loss and nonlinearity', Journal of Econometrics 140(2), 884-918. 
Patton, A. J. \& Timmermann, A. (2007b), 'Testing forecast optimality under unknown loss', Journal of the American Statistical Association 102, 1172-1184.

Pesaran, M. H. (1984), Expectations formation and macroeconomic modelling, in P. Malgrange \& P. Muet, eds, 'Contemporary Macroeconomic Modelling', Blackwell, Oxford, pp. 27-55.

Pesaran, M. H. (1987), The limits to rational expectations, Basil Blackwel, Oxford.

Pesaran, M. H. \& Weale, M. R. (2006), Survey Expectations, in G. Elliott, C. W. J. Granger \& A. Timmermann, eds, 'Handbook of Economic Forecasting Volume 1', North-Holland, pp. 715-776.

Shannon, C. (1948), 'A mathematical theory of communication', The Bell Systems Technical Journal 27, 379-423, 623-656.

Souleles, N. S. (2004), 'Expectations, heterogeneous forecast errors, and consumption: Micro evidence from the Michigan consumer sentiment surveys', Journal of Money, Credit and Banking 36, 39-72.

Stock, J. \& Watson, M. (2002), 'Macroeconomic forecasting using diffusion indexes', Journal of Business and Economic Statistics 20(2), 147-162.

Trichet, J. (2009), Comments at Press Conference. 6th August 2009. www.ecb.int/press/presscon/2009/html/is090806.en.html.

Wallis, K. F. (1980), 'Econometric implications of the rational expectations hypothesis', Econometrica 48(1), 49-73.

Wheeler, T. (2010), 'What can we learn from surveys of business expectations?', Bank of England Quarterly Bulletin 2010 Q3, 190-198.

Zellner, A. (1986), 'Biased predictors, rationality and the evaluation of forecasts', Economics Letters 21, 45-48. 